\title{
ASSESSMENT AND UTILIZATION OF DRUG INFORMATION SERVICES AND CREATING AWARENESS FOR ENHANCED UTILIZATION OF DRUG INFORMATION CENTER IN A TERTIARY CARE TEACHING HOSPITAL
}

\author{
ANN VARSHA PETER, ANUSHA MURALI, TILU TOMY, SUSHILKUMAR P LONDHE*
}

Department of Pharmacy Practice, Bapuji Pharmacy College, Davanagere, Karnataka, India. Email: Isushil2002@gmail.com Received: 19 January 2017, Revised and Accepted: 24 February 2017

\section{ABSTRACT}

Objective: The objective of this study is to assess the utilization of drug information services and create awareness for enhanced utilization of drug information center in the hospital.

Methods: A retro-prospective observational study conducted from September 2015 to February 2016. The data obtained from drug information (DI) request, documentation, and feedback forms are analyzed for the parameters such as professional status of enquirer, mode of receipt of query, purpose of enquiry, time frame to reply, and references used. Awareness about drug information services was created in the hospital by circulating brochures and interacting with health-care professionals.

Results: A total of 943 queries were retrospectively analyzed. Most of the queries obtained from a post-graduate/intern (50.27\%), during ward rounds (57.48\%), and asked for updating knowledge (76.35\%). Frequently asked questions were about indications of drugs (18.60\%). Mostly answers given as printed (66.70\%), replied within a day (46.45\%) by using Micromedex (54.72\%). The majority of the enquirers rated the DI services as good (54.93\%). A total of 394 queries were prospectively analyzed. Most of the queries obtained from physicians (42.23\%), during ward rounds (59.89\%), and asked for updating knowledge (49.49\%). Frequently asked questions were about adverse drug reaction (21.28\%). The mode of reply to the queries given mostly in printed format (41.14\%), replied within 2-4 hrs (33.75\%) by using Micromedex (40.56\%). The majority of the enquirers rated the DI services as good (46.98\%).

Conclusion: The drug information services provided were useful for various health-care professionals to maintain rational drug therapy by giving unbiased and well-reviewed information.

Keywords: Drug information center, Drug information service, Drug information query, Micromedex drug database.

(c) 2017 The Authors. Published by Innovare Academic Sciences Pvt Ltd. This is an open access article under the CC BY license (http://creativecommons. org/licenses/by/4. 0/) DOI: http://dx.doi.org/10.22159/ajpcr.2017.v10i5.17180

\section{INTRODUCTION}

Drug information service is the service that encompasses the activities of specially trained individuals to provide accurate, unbiased, factual information, primarily in response to patient-oriented drug problems received from various members of the health-care team [1]. These activities are undertaken by the especially well-trained individuals, i.e., clinical pharmacist and doctor of pharmacy professionals who are qualified and registered under the Board of State Pharmacy Council in providing information to optimizing the drug therapy [2]. Providing drug information is a fundamental responsibility of all pharmacists irrespective of the practice setting [3]. The World Health Organization (WHO) stated that drug information center (DIC) is a core component of national programs to promote the rational use of drugs [4]. Drug information is key to preventing medication errors. Such information leads to enhanced quality of patient care and thus improved patient outcome [5].

Drug use is a complex practice even a small mistake, and incomplete information has catastrophic implication in patients and results into noncompliance, therapeutic failure, overdosage, medication errors, drug interactions and adverse drug reactions (ADRs), which concurrently lead to ineffective and irrational use of drugs. According to the WHO, $60 \%$ of drug related problems can be prevented with appropriate information of drugs [6]. Lack of time is some of the factors that make the physicians unable to update their knowledge about drugs which have resulted in an increasing demand for independent and unbiased information about drugs for better patient care [7]. Information must be available in a format suitable for health practitioners and relevant to current clinical practice [8]. In India, irrational use of drugs is common, and this has led to antibiotic resistance, ADRs, drug interactions, and other drug-related problems [9].

The primary function of the center is in accessing to the drug information source and dissemination of the same to the requestor [10]. Possible sites for the location of a drug information center include the ministry of health, hospital, university, non-government organization, and the private sector [11]. According to available data, these services can help to detect and prevent ADRs, medication errors and promote rational use of drugs [12]. The center was intended to be utilized as a source center where people could call or contact health-care professionals and ask medicine-related questions [13]. DICs aims to achieve the quality use of medicines by providing and communicating timely, accurate, balanced and comprehensive information on drugs and their usage [14].

In 1962, the first drug information center was initialized at the University of Kentucky Medical Center [15]. In India, Rosemary sharp, a missionary from UK, started the first drug information center at Christian Medical College, Vellore in the early 1970s [16]. Later the Karnataka State Pharmacy Council (KSPC) established its Drug Information Centre in August 1997 to disseminate unbiased drug information to healthcare professionals. The center has been registered with International Register of Drug Information Services [17]

Recognizing the need to provide organized drug information to health-care professionals as well as consumers, the WHO India Country Office in collaboration with the KSPC has supporting the establishment of 5 drug information centers. These centers have 
been established in Haryana (Sirsa), Chattisgarh (Raipur), Rajasthan (Jaipur), Assam (Dibrugarh), and Goa (Panaji). They started functioning in 2007 [18].

Quality assurance in DIS can be deciding what services are to be provided, providing them, measuring how well the services were provided, and if the services were not found to be acceptable or optimal, undertaking some correctional activity to ensure that future services will be acceptable [19]. In developing countries like India, there are only a few DICs and are limited by lack trained staff, funds and by limited access to current literature. This clearly signifies that there is a need for periodic evaluation of mode of functioning and quality of services provided by the DIC [20]. Pharmacists are challenged with keeping up to date with an increasing number of new drugs and literature [21]

WHO recognizes independent drug information centers as a core component of national programs to promote the rational use of drugs [22].

In 2013, the drug information center was established by Bapuji Pharmacy College in S.S Institute of Medical Sciences and Research Centre (SSIMS and RC), Karnataka. The center focuses on providing unbiased drug information, well referenced, critically evaluated and up to date information which promotes the safe and effective use of medication. Clinical pharmacists and the staff working in our department were specially trained under drug information center with adequate knowledge on clinical research, pharmacology, pharmaceutics, pharmacotherapeutics, and statistics.

\section{Objectives}

The objective of the study was to assess the utilization of drug information services and creating awareness for enhanced utilization of DIC in a tertiary care teaching hospital.

\section{METHODS}

A retro-prospective observational analysis of DIC was conducted in a tertiary care teaching hospital in Davanagere for 6-months.

\section{Inclusion criteria}

- Drug information provided to various health-care professionals (doctors, nurses, paramedical).

- Drug queries generated or requisitioned from various departments in the entire hospital.

Exclusion criteria

- Drug information provided to patients at the time of patient counselling.

- Any other drug information provided to the patient through direct access to DIC

\section{Ethical issues}

The ethical clearance for the study was obtained from the Institutional Ethical Committee of Bapuji Pharmacy College, Davangere.

\section{Study procedure}

The drug information request and documentation forms from the DIC were retro-prospectively analyzed for 6-months, for collecting the following parameters such as professional status of enquirer, speciality of practice, mode of receipt of query, purpose of enquiry, time frame to reply, and references used. The quality of services provided by the DIC was assessed on feedback questionnaire given by the enquirer, which comprised questions pertaining to awareness, utilization, opinion, etc. Education program was conducted in the hospital for the students of Pharm. D. regarding their role in patient care and the systematic approach to answering drug information enquiries. Awareness about DIC and its services was created in the hospital by circulating brochures and interacting with health-care professionals.

\section{RESULTS}

Retrospective analysis

A total number of 943 queries were received to drug information center of SSIMS and RC from January 2013 to August 2015 (Table 1).

Among these, most of the queries were given by post-graduate (PG)/ interns $474(50.27 \%)$ followed by physician $282(29.90 \%)$ and pharmacist 68 (7.21\%) (Table 2).

Out of 943 queries, 542 (57.48\%) were obtained during ward rounds, $393(41.67 \%)$ via direct access and $8(0.85 \%)$ by others (Table 3 ).

Among these, 719 (76.25\%) were enquired to update knowledge, $221(23.43 \%)$ for better patient care and $3(0.32 \%)$ for other purposes (Table 4).

Our retrospective analysis illustrates that most of the queries were asked regarding indication 358 (18.60\%) and least regarding poisoning $22(1.14 \%)$ (Table 5).

Around $629(66.70 \%)$ queries were given as printed material, $197(20.89 \%)$ as written, $62(6.58 \%)$ as verbal and 55 (5.83\%) in both written and verbal form (Table 6).

Time frame for reply for the majority of queries was within a day (46.45\%) followed by within $2-4 \mathrm{hrs}(27.78 \%)$ (Table 7$)$

Table 1: Year-wise distribution of queries

\begin{tabular}{llll}
\hline S. No. & Year & $\begin{array}{l}\text { Total number } \\
\text { of queries } \\
\text { received }\end{array}$ & $\begin{array}{l}\text { Average } \\
\text { number } \\
\text { of queries } \\
\text { received }\end{array}$ \\
\hline 1 & 2013 (January-December) & 237 & 20 \\
2 & 2014 (January-December) & 401 & 33 \\
3 & 2015 (January-August) & 305 & 38 \\
\hline
\end{tabular}

Table 2: Professional status of enquirer

\begin{tabular}{lll}
\hline S. No. & $\begin{array}{l}\text { Professional status of } \\
\text { enquirer }\end{array}$ & Number of queries (\%) \\
\hline 1 & PG/Intern & $474(50.27)$ \\
2 & Physician & $282(29.90)$ \\
3 & Pharmacist & $68(7.21)$ \\
4 & Nurse & $64(6.79)$ \\
5 & Surgeon & $37(3.92)$ \\
6 & Others & $8(0.85)$ \\
7 & Resident & $6(0.64)$ \\
8 & Dermatologist & $4(0.42)$ \\
\hline PG: Post-graduate
\end{tabular}

Table 3: Mode of receipt of the queries

\begin{tabular}{lll}
\hline S. No. & Mode of receipt of the query & Number of queries (\%) \\
\hline 1 & During ward rounds & $542(57.48)$ \\
2 & Direct access & $393(41.67)$ \\
3 & Others & $8(0.85)$ \\
4 & Telephone & $0(0)$ \\
\hline
\end{tabular}

Table 4: Reason of requisition

\begin{tabular}{lll}
\hline S. No. & Reason of requisition & Number of queries (\%) \\
\hline 1 & Update knowledge & $719(76.25)$ \\
2 & Better patient care & $221(23.43)$ \\
3 & Others & $3(0.32)$ \\
\hline
\end{tabular}


About 516 (54.72\%) queries were answered by using Micromedex followed by textbooks 243 (25.77\%), websites 107 (11.35\%), and journals 77 (8.16\%) (Table 8).

Nearly 77 (8.16\%) queries were answered by using primary resources, $623(66.07 \%)$ by secondary resources and $243(25.77 \%)$ by using tertiary resources (Table 9).

The majority of the requesters rated the provided drug information as good 518 (54.93\%) and satisfactory 142 (15.06\%) (Table 10).

\section{Prospective analysis}

A total of 394 queries were received from September 2015 to February 2016. The average number of queries received per month was 67 . Most of the queries were obtained in the month of February (20.81\%) (Table 11).

Table 5: Types of drug query

\begin{tabular}{lll}
\hline S. No. & Types of drug query & Number of queries (\%) \\
\hline 1 & Indication & $358(18.60)$ \\
2 & ADR & $289(15.02)$ \\
3 & Dosage/administration & $271(14.08)$ \\
4 & Drug therapy & $228(11.84)$ \\
5 & Others & $192(9.97)$ \\
6 & Pharmacokinetics & $178(9.25)$ \\
7 & Interactions & $118(6.13)$ \\
8 & Availability/cost & $108(5.61)$ \\
9 & Efficacy & $100(5.19)$ \\
10 & Pregnancy/lactation & $61(3.17)$ \\
11 & Poisoning & $22(1.14)$ \\
\hline
\end{tabular}

Table 6: Mode of reply

\begin{tabular}{lll}
\hline S. No. & Mode of reply & Number of queries (\%) \\
\hline 1 & Printed material & $629(66.70)$ \\
2 & Written & $197(20.89)$ \\
3 & Verbal & $62(6.58)$ \\
4 & Both (written and verbal) & $55(5.83)$ \\
\hline
\end{tabular}

Table 7: Time frame for reply

\begin{tabular}{lll}
\hline S. No. & Time frame to reply & Number of queries (\%) \\
\hline 1 & Within a day & $438(46.45)$ \\
2 & Within 2-4 hrs & $262(27.78)$ \\
3 & Within 1-2 days & $145(15.38)$ \\
4 & Immediately & $98(10.39)$ \\
\hline
\end{tabular}

Table 8: Data sources used for information

\begin{tabular}{lll}
\hline S. No. & Sources used for information & Number of queries (\%) \\
\hline 1 & Micromedex & $516(54.72)$ \\
2 & Textbooks & $243(25.77)$ \\
3 & Website & $107(11.35)$ \\
4 & Journals & $77(8.16)$ \\
5 & Others & $0(0)$ \\
\hline
\end{tabular}

Table 9: Categorization of data sources used

\begin{tabular}{lll}
\hline S. No. & Data sources used & Number of queries (\%) \\
\hline 1 & Primary resources & $77(8.16)$ \\
2 & Secondary resources & $623(66.07)$ \\
3 & Tertiary resources & $243(25.77)$ \\
\hline
\end{tabular}

Out of 394 queries, most of the queries were given by physicians 166 (42.13\%) followed by PG/interns 87 (22.08\%) and surgeon $50(12.69 \%)$ (Table 12).

Out of 394 queries, 236 (59.89\%) were obtained during ward rounds, $140(35.53 \%)$ via direct access, $10(2.55 \%)$ by others and $8(2.03 \%)$ through telephone (Table 13).

Among the queries, 195 (49.49\%) were enquired to update knowledge, $194(49.23 \%)$ for better patient care and 5 (1.28\%) for other purposes (Table 14).

Our prospective analysis illustrates that most of the queries were asked regarding ADR of the drug 202 (21.28\%) and least regarding poisoning $9(1.09 \%)$ (Table 15).

Table 10: Quality of DI provided

\begin{tabular}{lll}
\hline S. No. & Quality of DI provided & Number of queries (\%) \\
\hline 1 & Good & $518(54.93)$ \\
2 & Satisfactory & $142(15.06)$ \\
3 & Excellent & $122(12.94)$ \\
4 & Can improve & $98(10.39)$ \\
5 & Fair & $60(6.36)$ \\
6 & Poor & $3(0.32)$ \\
\hline
\end{tabular}

Table 11: Month-wise distribution of received queries

\begin{tabular}{lll}
\hline S. No. & Months & Number of queries (\%) \\
\hline 1 & September 2015 & $52(13.20)$ \\
2 & October 2015 & $68(17.26)$ \\
3 & November 2015 & $45(11.42)$ \\
4 & December 2015 & $70(17.77)$ \\
5 & January 2016 & $77(19.54)$ \\
6 & February 2016 & $82(20.81)$ \\
\hline
\end{tabular}

Table 12: Professional status of enquirer

\begin{tabular}{lll}
\hline S. No. & $\begin{array}{l}\text { Professional status of } \\
\text { enquirer }\end{array}$ & Number of queries (\%) \\
\hline 1 & Physician & $166(42.13)$ \\
2 & PG/interns & $87(22.08)$ \\
3 & Surgeon & $50(12.69)$ \\
4 & Nurse & $47(11.93)$ \\
5 & Dermatologist & $17(4.32)$ \\
6 & Pharmacist & $17(4.32)$ \\
7 & Resident & $9(2.28)$ \\
8 & Others & $1(0.25)$ \\
\hline
\end{tabular}

Table 13: Mode of receipt of queries

\begin{tabular}{lll}
\hline S. No. & Mode of receipt of queries & Number of queries (\%) \\
\hline 1 & During ward rounds & $236(59.89)$ \\
2 & Direct access & $140(35.53)$ \\
3 & Other & $10(2.55)$ \\
4 & Telephone & $8(2.03)$ \\
\hline
\end{tabular}

Table 14: Reason of requisition

\begin{tabular}{lll}
\hline S. No. & Reason of requisition & Number of queries (\%) \\
\hline 1 & Update knowledge & $195(49.49)$ \\
2 & Better patient care & $194(49.23)$ \\
3 & Others & $5(1.28)$ \\
\hline
\end{tabular}


Our prospective study has shown that 162 (41.14\%) queries were given as printed material, $129(32.74 \%)$ as written, $58(14.70 \%)$ as both written and verbal and $45(11.42 \%)$ in verbal form (Table 16).

Time frame for reply for 133 (33.75\%) queries were within 2-4 hrs, $117(29.69 \%)$ were within a day, 93 (23.66\%) were within 1-2 days and for $51(12.90 \%)$ were immediately (Table 17).

About 203 (41.17\%) queries were answered by using Micromedex followed by textbooks 135 (27.38\%), journals 100 (20.28\%) and websites 55 (11.17\%) (Table 18).

Nearly 100 (20.28\%) queries were answered by using primary resources, $258(52.34 \%)$ by secondary resources and $135(27.38 \%)$ by using tertiary resources (Table 19).

Majority of the requesters rated the provided drug information as good 185 (46.95\%) and excellent 74 (18.77\%) (Table 20).

By comparing the results of both retrospective and prospective studies indicates an average of 29 queries/month was received in retrospective analysis and 67 queries/month in prospective analysis period.

\section{DISCUSSION}

Drug information service can help to detect and prevent ADRs, medication errors and promote rational use of drugs. Therefore, these centers can positively improve the outcome of therapy.

There was a gradual increase in the number of utilization of drug information service during the prospective analysis period. It was due to the impact of awareness created in the hospital regarding drug information center.

After analyzing the queries, the physicians maximally utilized the drug information services which comprise more than $40 \%$ of consult volume compared to PG/interns, surgeons and other health-care professionals.

\section{Table 15: Types of drug query}

\begin{tabular}{lll}
\hline S. No. & Types of drug query & Number of queries (\%) \\
\hline 1 & ADR & $202(21.28)$ \\
2 & Indications & $152(16.32)$ \\
3 & Dosage/administration & $138(14.52)$ \\
4 & Efficacy & $72(8.72)$ \\
5 & Drug therapy & $71(8.07)$ \\
6 & Interactions & $64(7.27)$ \\
7 & Others & $48(5.45)$ \\
8 & Pregnancy/lactation & $47(5.34)$ \\
9 & Availability/cost & $46(5.23)$ \\
10 & Pharmacokinetics & $40(4.55)$ \\
11 & Poisoning & $9(1.09)$ \\
\hline
\end{tabular}

ADR: Adverse drug reactions

Table 16: Mode of reply

\begin{tabular}{lll}
\hline S. No. & Mode of reply & Number of queries (\%) \\
\hline 1 & Printed material & $162(41.14)$ \\
2 & Written & $129(32.74)$ \\
3 & Both (written and verbal) & $58(14.70)$ \\
4 & Verbal & $45(11.42)$ \\
\hline
\end{tabular}

Table 17: Time frame for reply

\begin{tabular}{lll}
\hline S. No. & Time frame to reply & Number of queries (\%) \\
\hline 1 & Within 2-4 hrs & $133(33.75)$ \\
2 & Within a day & $117(29.69)$ \\
3 & Within 1-2 days & $93(23.66)$ \\
4 & Immediately & $51(12.90)$ \\
\hline
\end{tabular}

Most of the queries were received during ward rounds (59.89\%), which could be attributed to the easy accessibility of clinical pharmacist that prompts other health-care professionals to utilize the services. This was similar to the results of the studies conducted by Subash et al. (2009) and Venkatraghavan et al. In the study conducted by Subash et al., 44\% of queries received during ward round, whereas it was estimated as $61.5 \%$ in the study of Venkatraghavan et al.

The reason of requisition of most of the queries was to update knowledge $(49.49 \%)$ and for better patient care $(49.23 \%)$. This is comparable with the study conducted by Jeevangi et al., which shown $56.56 \%$ and $31.15 \%$, respectively.

In this study, queries on ADR (21.28\%) were predominant. This result closely matches with the findings in a study done by Rajanandh et al. which showed that maximum queries were on ADR (35.90\%). While in the study conducted by Subash et al., in 2013, most commonly asked questions were on drug therapy (34\%). Our findings indicate that physicians give more importance to ADRs of various drugs.

In this study, $33.75 \%$ of the queries were answered within 2-4 hrs, which is in contrast to the study findings done by Jayasutha et al. where majority of the queries were replied within a day (86\%). This is because of the ready availability of authenticated drug information software and ease of getting information from these sources.

In our study, most of the queries were answered in printed material (41.14\%). This result was similar to the result $(52.46 \%)$ of the study done by Mudigubba et al.

To answer the queries, primary, secondary and tertiary sources were used. Among them, most of the queries were answered by using Micromedex (41.17\%). These findings are similar to the studies conducted by Aida et al. and Jeevangi et al. where it was $37.3 \%$ and $52.45 \%$, respectively. The availability of recent and relevant information in Micromedex makes clinical pharmacists to use it as a major source of providing DI.

Feedback responses clearly demonstrated that majority of enquirers were very much satisfied with the performance of the service and

Table 18: Data sources used for information

\begin{tabular}{lll}
\hline S. No. & $\begin{array}{l}\text { Data sources used for } \\
\text { information }\end{array}$ & Number of queries (\%) \\
\hline 1 & Micromedex & $203(41.17)$ \\
2 & Textbooks & $135(27.38)$ \\
3 & Journals & $100(20.28)$ \\
4 & Websites & $55(11.17)$ \\
5 & Others & $0(0)$ \\
\hline
\end{tabular}

Table 19: Categorization of data sources used

\begin{tabular}{lll}
\hline S. No. & Data sources used & Number of queries (\%) \\
\hline 1 & Primary resources & $100(20.28)$ \\
2 & Secondary resources & $258(52.34)$ \\
3 & Tertiary resources & $135(27.38)$ \\
\hline
\end{tabular}

Table 20: Quality of the DI provided

\begin{tabular}{lll}
\hline S. No. & Quality of the DI provided & Number of queries (\%) \\
\hline 1 & Good & $185(46.95)$ \\
2 & Excellent & $74(18.77)$ \\
3 & Satisfactory & $56(14.21)$ \\
4 & Fair & $46(11.68)$ \\
5 & Can improve & $33(8.38)$ \\
6 & Poor & $0(0)$ \\
\hline
\end{tabular}


rated as good (46.95\%) and excellent (18.77\%). Similar to the study conducted by Walli et al. where it showed that majority of the enquirers rated the provided drug information services as good $(48.90 \%)$

\section{CONCLUSION}

Awareness for enhanced utilization of drug information services is an effective tool for better patient care. Therefore, it is necessary to perform such studies frequently for accessing and analyzing the utilization of drug information services in the hospital.

\section{REFERENCES}

1. Beena G, Rao PG. Assessment and evaluation of drug information services provided in a South Indian teaching hospital. Indian J Pharmacol 2005;37(5):315-18.

2. Mudigubba MK, Sowmya B, Dinesh R, Karthik M, Alpesh KN, Yoganada R, et al. Evaluation of performance of drug information centre providing quality of information services to health care professionals in a tertiary care teaching hospital of south India. Innov Pharm Pharmacother 2013;1(2):81-90.

3. Subash VK, Vijayalaxmi C, Alekhya P. Performance of drug information centre by a clinical pharmacist in a tertiary care teaching hospital, Warangal, Andhra Pradesh, India. Int J Pharm Pract Drug Res 2013;3(1):1-5.

4. Ming MW, Heba A, Ahmed A, Nahla HK, Yasmin HE. Quality evaluation and survey of the essential need for drug information centers. Int J Pharm Pharm Sci 2016;8(11):137-43.

5. Jeevangi VM, Neelkantreddy P, Anand BG, Hinchageri SS, Manjunath G, Shantveer H. Assessment and evaluation of drug information service provided by pharmacy practice department based on enquirers perspective. Int Res J Pharm 2012;3(10):193-9.

6. Walli M, Samreen A, Satheesh M, Ramya NG, Saradha S, Uma MR. Drug information service: A valuable service for better patient care provided by clinical pharmacists in government hospital. World $\mathrm{J}$ Pharm Res 2015;4(3):1552-60.

7. Rekha MB, Rekha MS, Purushotham N. Assessment and evaluation of drug information needs of physicians treating Type 2 diabetes mellitus with co-existing hypertension in a tertiary care hospital. Res Rev J Med Health Sci 2014;3(2):146-50.

8. Requirements for Drug Information Centres (FIP Pharm Inf Sec). Available from: http:/www.fip.org/files/fip/PI/ RequirementsforDrugInformationCentres.pdf. [Last cited on 2015 Oct 22].
9. Rajanandh MG, Ruby V, Ramasamy C. Assessment of drug information services in a south Indian tertiary care hospital in Kanchipuram district. Int J Pharm Pharm Sci 2011;3(3):273-6.

10. Suresh CP. The performance of drug information centre at the university of Kansas medical centre, Kansas city, USA-experiences and evaluations. Indian J Phamacol 2002;34:123-9.

11. Joshi MP. Drug information service at teaching hospitals in developing countries. Indian J Pharmacol 1998;30(1):1-5.

12. Taher EM, Mohammad T, Mohammad RJ, Mir HH, Kaveh E, Iman K et al. A two year utilization of the pharmacist-operated drug information centre in Iran. J Res Pharm Pract 2014;3(4):117-22.

13. Aida AA, Shafinaz MY, Suhaidah NJ, Mohd SA. Drug information service awareness program and its impact on characteristics of inquiries at DIS unit in Malaysian public hospital. Arch Pharm Pract 2013;4(1):9-14.

14. Chhetri AK, Palaian S, Mishra P. Drug information services in Nepal: The changing perspectives. Kathmandu Univ Med J (KUMJ) 2008;6(1):117-21

15. Mahendrakumar BJ, Sandeep A, Bhimaray SK, Katti RV, Ramanth KV. Assessment and evaluation of drug information services provided by the clinical pharmacists in a rural tertiary care teaching hospital of South India. RGUHS J Pharm Sci 2011;1(1):26-30.

16. Rajan MS, Fayazkhan M, Kishor GS, Leelavathi DA, Rao PG. Evaluation of drug information service provided by clinical pharmacy department based on provider and enquirers perspective. Indian $\mathrm{J}$ Pharm Pract 2008;1(1):37-44.

17. Lakshmi PK, Gundu RD, Gore SB, Shyamala B. Drug information service to doctors of Karnataka, India. Indian $\mathrm{J}$ Pharmacol 2003;35:245-7.

18. Subash VK, Vijayalaxmi C. Quality of services provided by the drug information centre of the pharmacy practice department in a tertiary care teaching hospital at Warangal district, Andhra Pradesh, India. Indian J Hosp Pharm 2012;49:151-6.

19. Jayasutha J, Ashok KM, Sreeram S, Monic JN. Statistical survey and evaluation of drug information services at a tertiary care hospital. Res J Pharm Biol Chem Sci 2011;2(3):249-53.

20. Venkatraghavan S, Rama M, Leelavathi DA. Performance of a drug information centre in a South Indian teaching hospital. Int J Pharmtech Res 2010;2(1):390-403.

21. ASHP Guidelines on the Pharmacist's Role in Providing Drug Information. Available from: http://www.ashp.org/.doclibrary/ bestpractices/specificgdlmedinfo.aspx. [Last cited on 2015 Aug 29].

22. Chauhan N, Moin S, Pandey A, Mittal A, Bajaj U. Indian aspects of drug information resources and impact of drug information centre on community. J Adv Pharm Technol Res 2013;4(2):84-93. 